\title{
The sap of Acer okamotoanum decreases serum alcohol levels after acute ethanol ingestion in rats
}

\author{
YEONG-MIN YOO $^{1}$, EUI-MAN JUNG ${ }^{1}$, HA-YOUNG KANG ${ }^{2}$, IN-GYU CHOI $^{3}$, \\ KYUNG-CHUL CHOI ${ }^{1}$ and EUI-BAE JEUNG ${ }^{1}$
}

\author{
${ }^{1}$ Laboratory of Veterinary Biochemistry and Molecular Biology, College of Veterinary Medicine, Chungbuk National \\ University, Cheongju, Chungbuk 361-763; ${ }^{2}$ Division of Wood Chemistry and Microbiology, Department of Forest \\ Products, Korea Forest Research Institute, Seoul 130-712; ${ }^{3}$ Department of Forest Sciences, College of \\ Agriculture and Life Sciences, Seoul National University, Seoul 151-921, Republic of Korea
}

Received April 28, 2011; Accepted June 2, 2011

DOI: $10.3892 / \mathrm{ijmm} .2011 .724$

\begin{abstract}
In the present study, we examined whether Acer okamotoanum (A. okamotoanum) sap decreased the serum alcohol and acetaldehyde levels after acute ethanol treatment in a rat model. Male rats were orally administered 25,50 or $100 \%$ A. okamotoanum sap 30 min prior to oral challenge with $3 \mathrm{ml}$ of ethanol $(15 \mathrm{ml} / \mathrm{kg}$ of a $20 \%$ ethanol solution in water), and the blood concentrations of alcohol and acetaldehyde were analyzed up to $7 \mathrm{~h}$ after the treatment. Pre-treatment with the sap significantly decreased the blood ethanol and acetaldehyde concentrations after $5 \mathrm{~h}$ when compared with ethanol treatment alone (a negative control). The expression levels of liver alcohol dehydrogenase (ADH) and aldehyde dehydrogenase (ALDH) mRNA were increased significantly in animals pre-treated with A. okamotoanum sap when compared with negative and positive controls. The data suggest that sap pretreatment enhanced the alcohol metabolism rate in the rat liver. To investigate the involvement of mitochondrial regulation in the ethanol-induced hepatocyte apoptosis, we carried out an immunohistochemical analysis of Bax and Bcl-2. Pre-treatment with sap significantly decreased Bax expression and increased Bcl-2 expression $7 \mathrm{~h}$ after ethanol administration when compared with the negative control. The data suggest that $A$. okamotoanum sap pre-treatment may reduce the alcohol-induced oxidative stress in the rat liver.
\end{abstract}

\section{Introduction}

Ethanol intake has been known to reduce stress in humans; however, excessive ethanol consumption leads to serious social

Correspondence to: Dr Eui-Bae Jeung, Laboratory of Veterinary Biochemistry and Molecular Biology, College of Veterinary Medicine, Chungbuk National University, Cheongju, Chungbuk 361-763, Republic of Korea

E-mail: ebjeung@chungbuk.ac.kr

Key words: Acer okamotoanum, acetaldehyde, alcohol dehydrogenase, aldehyde dehydrogenase and economic problems. In particular, alcoholic hangover and associated gastric ulcers are conditions that are prevalent in modern Korea. As various social stresses may lead to frequent alcohol intake and may result in deep gastric ulcers and liver disease, there is a need to develop drugs and functional foods containing natural products to improve these conditions. However, because of the toxicity and side effects of drugs, healthy drinks that contain safer natural products should be developed. Recently, the development of healthy functional foods that activate alcohol dehydrogenase (ADH) and aldehyde dehydrogenase (ALDH) has focused on the reduction of blood alcohol levels, whereas an effective material with detoxification properties that activates metabolic enzymes after acute ethanol dosage has not been identified.

More than $85 \%$ of ingested alcohol is metabolized in the liver, where ADH decomposes alcohol to acetaldehyde in the cytosol of hepatocytes, resulting in acetate production by ALDH in the mitochondrial matrix. The alcohol catalytic process is associated with $\mathrm{ADH}, \mathrm{ALDH}$, and the microsomal ethanol oxidizing system (MEOS). Because acetaldehyde is much more toxic than alcohol, it is involved in the metabolic abnormalities of liver disease induced by alcohol. In addition, acetaldehyde causes DNA damage and abnormal muscle development (1). Under normal conditions, acetaldehyde is rapidly converted to acetate by $\mathrm{ADH}$; therefore, very low levels of acetaldehyde should remain in the liver tissue or blood. ALDH also plays an important role in the elimination of acetaldehyde via oxidative reactions. Thus, the severity of liver disease can be proportional to the down-regulation of the activity of $\mathrm{ADH}$ or ALDH.

The sap of Acer okamotoanum (A.okamotoanum) contains a considerable amount of sugar and can be used as a drink or can be concentrated into a syrup by boiling $(2,3)$. The syrup is used as a sweetener on many foods. The concentration of sugar is considerably lower than that found in the sap of sugar maples. The A. okamotoanum tree trunk is tapped in the early spring, the sap flowing best on warm sunny days after a frost. The best sap production comes from cold-winter areas with continental climates. The sap of A. okamotoanum contains sugar and various minerals, and can prevent extreme dehydration and tiredness or fatigue $(2,3)$. In the present study, 
we examined whether A. okamotoanum sap decreases blood alcohol levels after acute ethanol treatment in a rat model. Our goal was to investigate the possibility of making available alcohol detoxification drinks containing A. okamotoanum sap.

\section{Materials and methods}

Experimental animals. Male Sprague-Dawley rats of six weeks of age were purchased from Samtaco (Osan, Kyunggi-do, South Korea), and were allowed to adapt to laboratory conditions (temperature, $20 \pm 2^{\circ} \mathrm{C}$, relative humidity, $50 \%$, light/dark cycle, $12 \mathrm{~h}$ ) for a week before being used for animal experiments. The Chungbuk National University Animal Care and Use Committee approved the experiments. All procedures were conducted in accordance with the Guide for Care and Use of Laboratory Animals published by the National Institutes of Health.

Experimental design of A. okamotoanum sap and alcohol treatments. There were six groups of animals: alcohol-untreated (normal, $n=6$ ), alcohol-treated (negative control, $n=6$ ), condition power (CJ Corp., Korea, $n=7$ ) plus alcohol-treated (positive control, $\mathrm{n}=7$ ), 25\% A. okamotoanum sap plus alcohol-treated $(\mathrm{n}=7), 50 \%$ A. okamotoanum sap plus alcohol-treated $(\mathrm{n}=7)$, and $100 \%$ A. okamotoanum sap plus alcohol-treated $(\mathrm{n}=7)$. The rats were given orally 25,50 or $100 \%$ A. okamotoanum sap $30 \mathrm{~min}$ prior to oral challenge with $3 \mathrm{ml}$ of ethyl alcohol $(15 \mathrm{ml} / \mathrm{kg}$ of $20 \%$ ethanol solution in water), and the blood concentrations of alcohol and acetaldehyde were analyzed up to $7 \mathrm{~h}$ after treatment. Rats were anesthetized with $\mathrm{CO}_{2}$ and blood was collected from the tail vein. Sera were separated by centrifugation at $2,500 \mathrm{xg}$ for $15 \mathrm{~min}$ and were used in the experiment described below.

Measurement of alcohol and acetaldehyde levels. Serum alcohol and acetaldehyde levels were assessed using an ethanol determination kit (Cat no. 10176290 035, R-Biopharm Enzymatic BioAnalysis, Roche, Germany) and an acetaldehyde determination kit (Cat no. 10668613 035, R-Biopharm Enzymatic BioAnalysis), respectively, according to manufacturer's instructions.

Determination of vitamin $C$. Extraction and quantitative determination of vitamin $\mathrm{C}$ contents of $A$. okamotoanum sap were performed with minor modifications according to the previous method (4). A volume of $0.25 \mathrm{ml}$ of $10 \%$ trichloroacetic acid was added to $1.25 \mathrm{ml}$ of A. okamotoanum sap in a microtube. After vigorous shaking, the tubes were kept in an ice bath for $5 \mathrm{~min}$ and centrifuged at $3000 \mathrm{rpm}$ for another $5 \mathrm{~min}$. In another microtube, $1.25 \mathrm{ml}$ of supernatant and $0.2 \mathrm{ml}$ of $0.2 \mathrm{M}$ Folin-Ciocaltue reagent (purchased from Sigma-Aldrich) were mixed and vortexed sufficiently. After $10 \mathrm{~min}$, the absorbance of the blue color developed was measured using a UV-visible spectrophotometer (Shimadzu, JP/UV-1601pc) at $760 \mathrm{~nm}$.

Determination of plant hormones. Auxin (indole-3-acetic acid, IAA), gibberellic acid (GA3), abscisic acid (ABA) and cytokinin (zeatin) were examined in A. okamotoanum sap. UV-visible spectrophotometer (Shimadzu, JP/UV-1601pc) was used to determine the amounts of IAA, GA3, ABA and zeatin. Freeze-dried A. okamotoanum sap (1 g) was added into $60 \mathrm{ml}$ methanol: chloroform: $2 \mathrm{~N}$ ammonium hydroxide $(12: 5: 3 \mathrm{v} / \mathrm{v} / \mathrm{v})$ and $25 \mathrm{ml}$ DI water. After shaking at $250 \mathrm{rpm}$ for $30 \mathrm{~min}$, the water phase was adjusted to $\mathrm{pH} 2.5$ and 7 by $1 \mathrm{~N} \mathrm{HCl}$ or $1 \mathrm{~N}$ $\mathrm{NaOH}$, and extracted three times with ethyl acetate $(15 \mathrm{ml})$ for free form IAA, GA3 and ABA at $\mathrm{pH} 2.5$, and for zeatin at $\mathrm{pH}$ 7.0. After an incubation period of $1 \mathrm{~h}$ at $70^{\circ} \mathrm{C}$, the same procedure was used for the isolation of the bound-form IAA, GA3, ABA and zeatin. Ethyl acetate was fully evaporated and dissolved with $1 \mathrm{ml}$ of methanol. Spectrophotometric determinination was carried out at $222 \mathrm{~nm}$ for IAA, $254 \mathrm{~nm}$ for GA3, $263 \mathrm{~nm}$ for ABA and $269 \mathrm{~nm}$ for zeatin and for all standards.

Reverse transcription-polymerase chain reaction ( $R T-P C R)$. Total-RNA was isolated by TRIzol reagent (Invitrogen Life Technologies, Carlsbad, CA), according to the manufacturer's instructions. The RNA was quantitated spectrophotometrically and $1 \mu \mathrm{g}$ was reverse transcribed using reverse transcriptase (Invitrogen Life Technologies) at $42^{\circ} \mathrm{C}$ for $1 \mathrm{~h}$ with $300 \mathrm{ng}$ of oligo(dt) in a $20-\mu 1$ reaction, according to the manufacturer's recommendations. The reactions contained $200 \mathrm{nM}$ of each oligonucleotide, $10 \mathrm{mM}$ Tris- $\mathrm{HCl}$ ( $\mathrm{pH} \mathrm{8.3),} 50 \mathrm{mM} \mathrm{KCl}$, $3.0 \mathrm{mM} \mathrm{MgCl}$, and 0.125 units of Taq polymerase (iNtRON Biotechnology, Inc., Seongnam, South Korea). The reactions were cycled 25 times at $94^{\circ} \mathrm{C}$ for $60 \mathrm{sec}, 60^{\circ} \mathrm{C}$ for $30 \mathrm{sec}$, and $72^{\circ} \mathrm{C}$ for $30 \mathrm{sec}$ in a DNA Thermalcycler (Applied Biosystems). Ten microliters of each sample were electrophoresed through a $1.5 \%$ agarose gel. The samples were subsequently visualized and quantitated by phosphorimager analysis (Molecular Dynamics, Sunnyvale, CA). The sequences of the oligonucleotides used for amplification were as follows: ADH forward, 5'-ACC ATC GAG GAC ATA GAA GTC-3'; ADH reverse, 5'-GTG GAC CCT GGG GTC ACC TT-3'; ALDH forward, 5'-GCT GTC AGC AAG AAA ACA TTC CCC-3'; ALDH reverse, 5'-CTT GTC AGC AGC CCA GCC AGC ATA ATA-3' (323-bp); CYP2E1 forward, 5'-GAC CTT TCC CTC TTC CCA TC-3'; CYP2E1 reverse, 5'-TCG GAG AAT GCT TAG GGA AA-3'; GAPDH forward, 5'-ATC CCA TCA CCA TCT TCC AG-3'; GAPDH reverse, 5'-CCT GCT TTC ACC ACC TTC TTG-3'.

Immunohistochemistry. The cellular localizations of Bax and Bcl-2 were examined by immunohistochemistry. Liver tissue was embedded in paraffin. Thin sections $(5 \mu \mathrm{m})$ were deparaffinized in xylene and then hydrated by washing them in descending grades of ethanol. Endogenous peroxidase activity was blocked by incubating the sections in a solution of $3 \%$ hydrogen peroxide in Tris buffered saline contain $0.1 \%$ Tween-20 (TBS-T) for $30 \mathrm{~min}$. Sections were incubated in $10 \%$ normal goat serum for $2 \mathrm{~h}$ at room temperature to block non-specific binding, followed by incubation with Bax (1:100 in 10\% NGS, Santa Cruz Biotechnology) or Bcl-2 antibody (1:100 in $10 \%$ NGS, Santa Cruz Biotechnology) at RT for overnight. After washing with TBS-T, sections were incubated with biotinylated mouse IgG secondary antibody (Vector Laboratories, Burlingame, CA) for $30 \mathrm{~min}$ at $37^{\circ} \mathrm{C}$, followed by incubation for $30 \mathrm{~min}$ at $37^{\circ} \mathrm{C}$. Diaminobenzidine (DAB) was used as a chromogen. Sections were counterstained with hematoxylin and then mounted in Canada Balsam. Images were captured using an Olympus DP controller and imaged under a microscope. Bax- and Bcl-2-immunostained cells were counted under a microscope and the results were analyzed. 


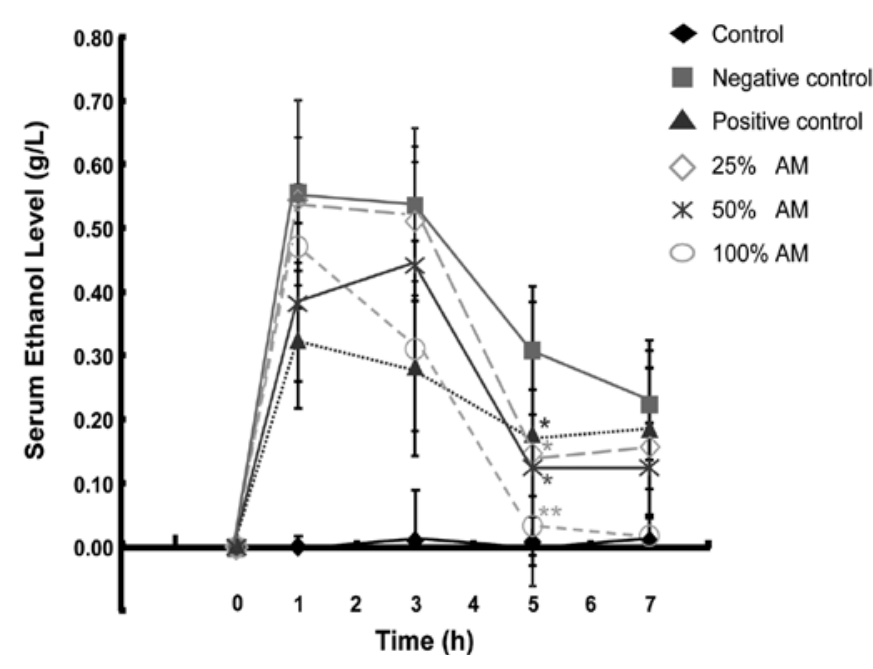

Figure 1. Effect of pre-treatment with A. okamotoanum sap on the time course of serum concentration of ethanol after ethanol administration. Rats were treated orally with 25,50 or $100 \%$ A. okamotoanum sap (AM) 30 min prior to oral challenge with $3 \mathrm{ml}$ of ethyl alcohol $(15 \mathrm{ml} / \mathrm{kg}$ of $20 \%$ ethanol solution in water) and the serum concentration of ethanol was analyzed up to 7 h. ${ }^{*} \mathrm{P}<0.05$ and ${ }^{* *} \mathrm{P}<0.01$ vs. negative control.

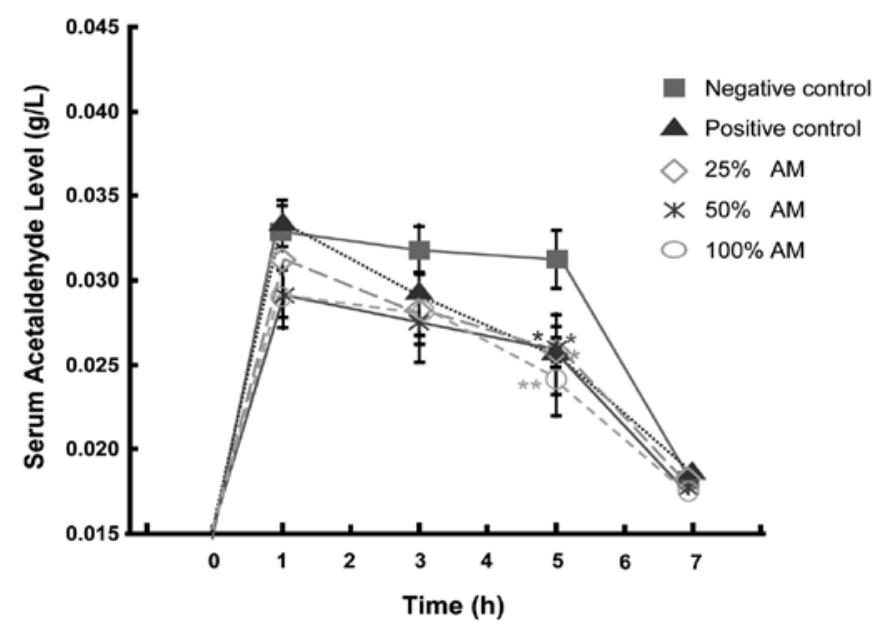

Figure 2. Effect of pre-treatment with A. okamotoanum sap on the time course of serum concentration of acetaldehyde after ethanol administration. Rats were treated orally with 25,50 or $100 \%$ A. okamotoanum sap (AM) $30 \mathrm{~min}$ prior to oral challenge with $3 \mathrm{ml}$ of ethyl alcohol $(15 \mathrm{ml} / \mathrm{kg}$ of $20 \%$ ethanol solution in water) and the serum concentration of acetaldehyde was analyzed up to $7 \mathrm{~h}$. ${ }^{*} \mathrm{P}<0.05$ and ${ }^{* *} \mathrm{P}<0.01$ vs. negative control.

Statistical analyses. In cases where a significant difference was found, a Tukey's test was performed to assess significant differences among experimental conditions. Analyses were performed using Prism Graph Pad (v.4.0). Results were expressed as means \pm SD. Differences between the two groups were considered significant for $\mathrm{P}<0.05$.

\section{Results}

It is useful to investigate and determine blood alcohol and acetaldehyde concentrations in the metabolic pathway of ethanol. In the present study, we examined whether A. okamotoanum sap decreased the blood alcohol and acetaldehyde levels after acute ethanol treatment in a rat model. Male rats were orally
A
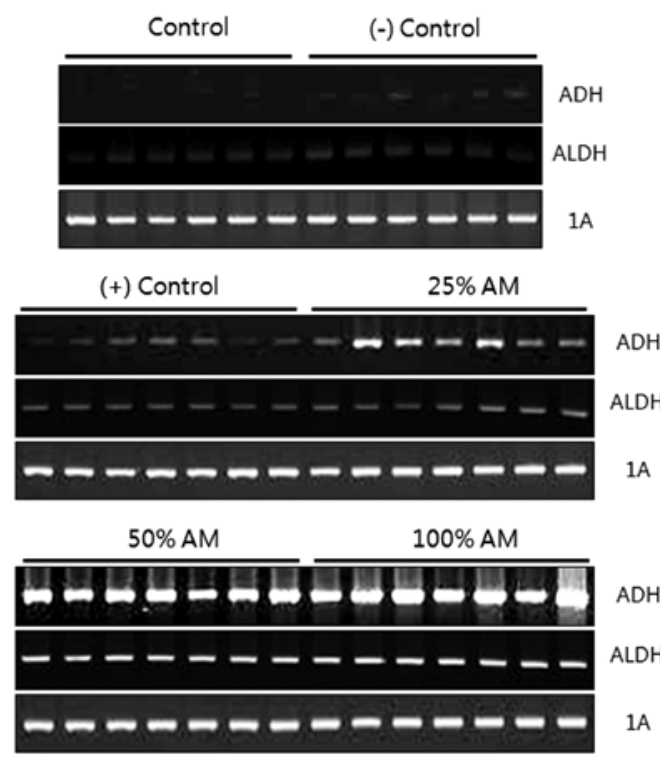

B

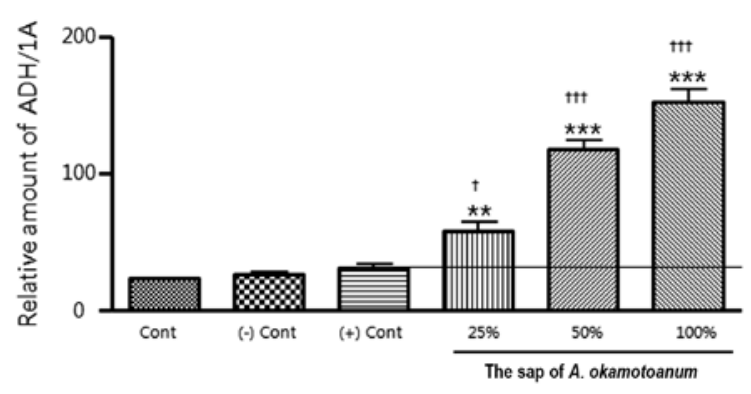

C

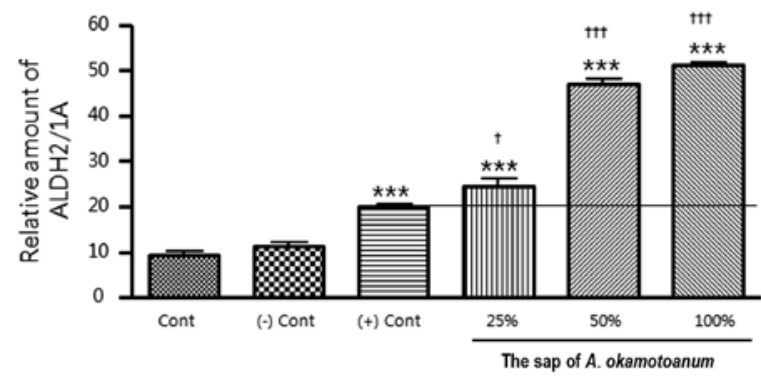

Figure 3. The mRNA expression levels of ADH and ALDH in animals pretreated with A. okamotoanum sap. Rats were treated orally with 25,50 or $100 \%$ A. okamotoanum sap (AM) 30 min prior to oral challenge with $3 \mathrm{ml}$ of ethyl alcohol (15 ml/kg of $20 \%$ ethanol solution in water) and RT-PCR was carried out $7 \mathrm{~h}$ after treatment (A). Quantitative analyses were performed using the NIH Image software 1.52 and Prism Graph Pad (v.4.0) (B). ${ }^{* *} \mathrm{P}<0.01$ and ${ }_{* * * * *} \mathrm{P}<0.001$ vs. negative control; ${ }^{\dagger} \mathrm{P}<0.05$ and ${ }^{\dagger+} \mathrm{P}<0.001$ vs. positive control.

administered 25,50 or $100 \%$ A. okamotoanum sap $30 \mathrm{~min}$ prior to oral challenge with $3 \mathrm{ml}$ of ethyl alcohol $(15 \mathrm{ml} / \mathrm{kg}$ of $20 \%$ ethanol solution in water) and the blood concentrations of alcohol and acetaldehyde were analyzed up to $7 \mathrm{~h}$ (Figs. 1 and 2). Pre-treatment with 25,50 or $100 \%$ A. okamotoanum sap significantly decreased the blood ethanol and acetaldehyde levels 3 and $5 \mathrm{~h}$ after ethanol treatment when compared with ethanol treatment alone (negative control) or with the positive control. The data suggest that A. okamotoanum sap may be useful as an alcohol detoxification pre-treatment for acute alcohol intake in a rat model. 
Table I. Vitamin C and plant hormone content (mg/l) of the sap of Acer okamotoanum.

\begin{tabular}{|c|c|c|c|c|c|c|}
\hline & \multicolumn{2}{|c|}{ Free form } & \multicolumn{2}{|c|}{ Bound form } & \multicolumn{2}{|c|}{ Total } \\
\hline & Mean & SD & Mean & SD & Mean & SD \\
\hline Vitamin C & & & & & 5.32 & 0.21 \\
\hline \multicolumn{7}{|c|}{ Plant hormones } \\
\hline IAA & 0.13 & 0.01 & 0.32 & 0.04 & 0.45 & 0.05 \\
\hline $\mathrm{GA}_{3}$ & 9.06 & 0.06 & 9.82 & 1.34 & 18.88 & 1.29 \\
\hline $\mathrm{ABA}$ & 0.16 & 0.01 & 0.23 & 0.06 & 0.39 & 0.07 \\
\hline Zeatin & 0.06 & 0.02 & 0.14 & 0.01 & 0.20 & 0.02 \\
\hline
\end{tabular}

Mean values with their standard errors.

A

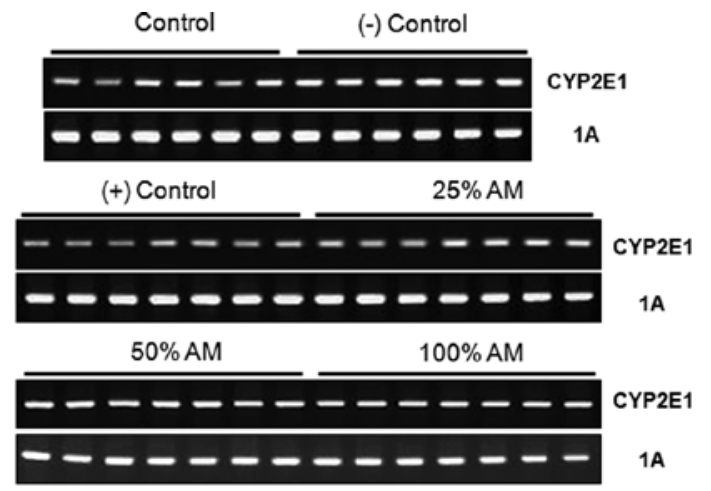

B

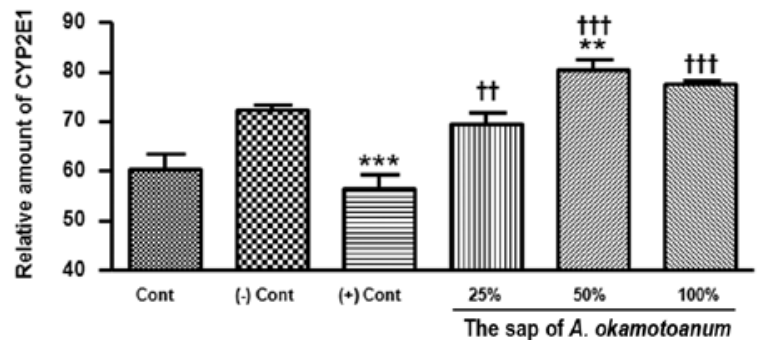

Figure 4. The mRNA expression levels of CYP2E1 in animals pretreated with A. okamotoanum sap. Rats were treated orally with 25,50 or $100 \%$ A. okamotoanum sap (AM) 30 min prior to oral challenge with $3 \mathrm{ml}$ of ethyl alcohol (15 ml/kg of $20 \%$ ethanol solution in water) and RT-PCR was carried out $7 \mathrm{~h}$ after treatment (A). Quantitative analyses were performed using the NIH Image software 1.52 and Prism Graph Pad (v.4.0) (B). ${ }^{* *} \mathrm{P}<0.01$ and ${ }^{* * * *} \mathrm{P}<0.001$ vs. negative control; ${ }^{\dagger} \mathrm{P}<0.01$ and ${ }^{\dagger \dagger} \mathrm{P}<0.001$ vs. positive control.

Alcohol is converted into acetaldehyde by ADH in the cytosol of liver cells, which results in the production of acetate by ALDH in the mitochondrial matrix. It is important to determine the expression levels of ADH and ALDH to assess ethanol metabolism in the liver. In the condition described above, the mRNA expression levels of liver ADH and ALDH were significantly increased in animals pre-treated with 25 , 50 or $100 \%$ A. okamotoanum sap when compared with negative or positive controls (Fig. 3A and B). The data suggest that pre-treatment with A. okamotoanum sap enhanced the alcohol metabolism rate in the rat liver. In addition, the mRNA expression levels of liver CYP2E1 were increased in animals pre-treated with 25,50 or $100 \%$ A. okamotoanum sap as compared to positive controls (Fig. 4), $7 \mathrm{~h}$ after alcohol administration, which suggests that pre-treatment with 25,50 or $100 \%$ A. okamotoanum sap may still activate liver metabolism $7 \mathrm{~h}$ after administration. The expression of CYP2E1 and the MEOS level are associated with a chronic state of alcohol abuse.

The content of vitamin C in A. okamotoanum sap was measured and its concentration was found to be $5.32 \mathrm{mg} / \mathrm{l}$ (Table I). According to our previous study, the vitamin C content of the Acer mono sap was 1.01-3.50 mg/l, which was almost two times lower than that of the A. okamotoanum sap. Plant hormones were also measured as both free and bound form. The contents of free form, bound form and total were $0.13,0.32$ and 0.45 for IAA, $9.06,9.82$ and 18.88 for GA3, $0.16,0.23$ and 0.39 for ABA, and $0.06,0.14$ and 0.20 for zeatin, respectively (Table I). Bound form contents were slightly higher than the free form, and GA3 content was exceedingly higher than other hormones.

Cahill et al (5) reviewed the mitochondrial regulation of ethanol-induced hepatocyte apoptosis and its association with proapoptotic Bax and mitochondrial reactive oxygen species (ROS) production. To investigate the role of the mitochondrial regulation in ethanol-induced hepatocyte apoptosis, we carried out an immunohistochemical analysis of Bax and Bcl-2 (Fig. 5). Pre-treatment with 25,50 or $100 \%$ A. okamotoanum sap significantly decreased Bax expression (Fig. 5B) and increased Bcl-2 expression (Fig. 5C) $7 \mathrm{~h}$ after treatment when compared with the negative control. These data suggest that A. okamotoanum sap pre-treatment may reduce the alcoholinduced oxidative stress in rat livers.

\section{Discussion}

In previous studies, Yang et al reported that the stilbene glycoside from A. okamotoanum leaves protects hepatocytes against $\mathrm{H}_{2} \mathrm{O}_{2}$-induced oxidative damage $(6,7)$. The sap of A. okamotoanum contains a considerable amount of sugar and various minerals $(2,3)$. In the present study, we examined the alcohol detoxification effect of the A. okamotoanum sap. This sap is believed to be beneficial for extreme dehydration and tiredness or fatigue because of its high mineral content. We previously reported the mineral content of this sap and 

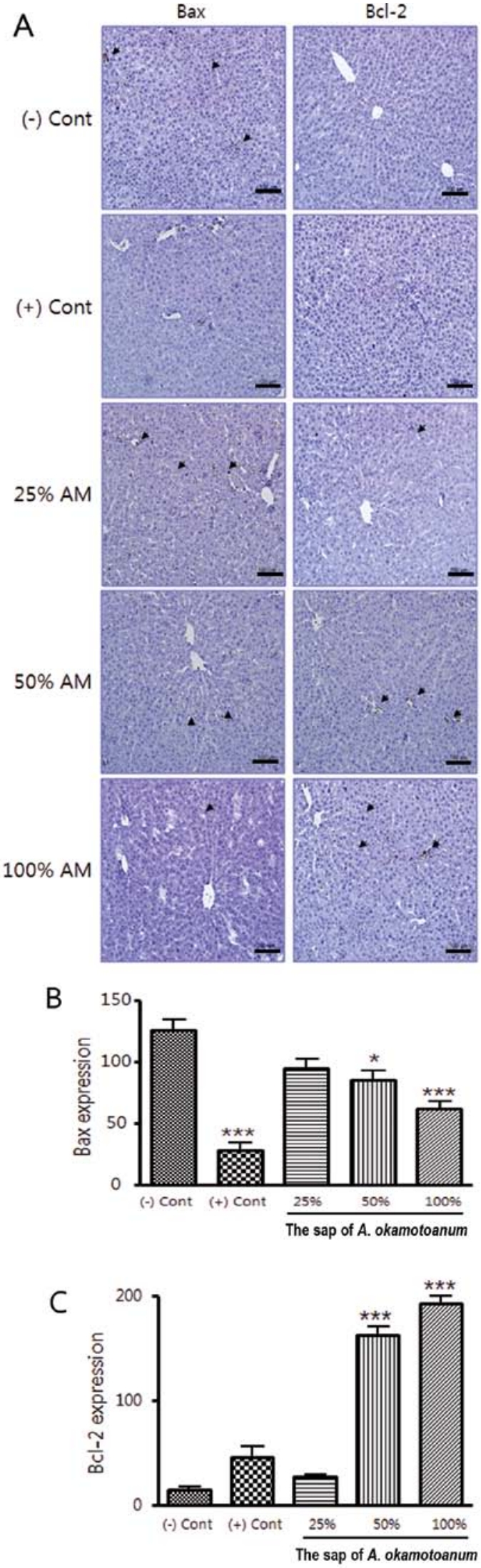

Figure 5. Effect of A. okamotoanum sap on the liver injury induced by acute alcohol intake. Rats were treated orally with 25,50 or $100 \%$ A. okamotoanum sap $30 \mathrm{~min}$ prior to oral challenge with $3 \mathrm{ml}$ of ethyl alcohol $(15 \mathrm{ml} / \mathrm{kg}$ of $20 \%$ ethanol solution in water) and immunohistochemistry was carried out $7 \mathrm{~h}$ after treatment (A). Quantitative analyses of Bax and Bcl-2 were performed using the NIH Image software 1.52 and Prism Graph Pad (v.4.0) (B). Arrows on the left column indicate Bax and arrows in the right column indicate $\mathrm{Bcl}-2$. ${ }^{*} \mathrm{P}<0.05$ and ${ }^{* * *} \mathrm{P}<0.001$ vs. negative control. Scale bar, $100 \mu \mathrm{m}$. compared it to commercial spring water (8). Our study showed that potassium, calcium, and magnesium are present at high levels in A. okamotoanum sap. The levels of calcium, magnesium, and potassium ions were 37-, 3.9- and 16-fold higher in the A.okamotoanum sap than in commercial spring water. We also demonstrated that the mineral content of the sap prevents or improves alcohol hangover symptoms.

Electrolytes and minerals are involved in most cellular activities and metabolism (9). They act on fluids and the acid-base balance in various compartments of the body. Both chronic and acute alcohol consumption have a physiological effect on the absorption, elimination, and serum concentrations of electrolytes and minerals, which include sodium, potassium, magnesium and calcium. Electrolyte disturbances may lead to severe, and even life-threatening, metabolic abnormalities, such as liver disease. Sodium and potassium assist in the maintenance of the body's electrolyte and water balance (10). In addition, these minerals play an important role in nerve conduction, muscle contraction, and transport of substances across membranes (11). Animal studies involving alcohol intake have shown significant retention of water, sodium, potassium, and chloride after the first week of daily alcohol ingestion (11). A. okamotoanum sap may maintain the acid-base balance by supplementing electrolytes and minerals into the intestine, and may suppress extreme dehydration and tiredness. The sap of A. okamotoanum contains sugar; however, the sugar levels have no significant effect on the rate of ethanol elimination or on the blood acetaldehyde concentration. Glucose and fructose significantly inhibit the metabolic alterations induced by ethanol (12). This report suggests that both fructose and glucose effectively inhibit the metabolic disturbances induced by ethanol; however, they do not affect the symptoms or signs of alcohol intoxication and hangover.

Self-control, moderation in alcohol consumption, and the identification of natural products for alcohol detoxification are not a satisfactory therapy for alcohol-induced liver damage. Alcohol clearance depends on the enzymatic conditions in the liver of each individual. Three known catalytic enzyme systems located in different subcellular hepatocyte compartments participate in the oxidation of alcohol: ADH in the cytoplasm, MEOS in the endoplasmic reticulum, and catalase in peroxisomes (13). The ingestion of alcohol leads to the rapid conversion of acetaldehyde to acetate by $\mathrm{ADH}$; therefore, very low levels of acetaldehyde should remain in the liver tissue or in the blood after alcohol consumption. ALDH also plays an important role in the elimination of acetaldehyde via oxidative reactions. Therefore, liver damage can be proportional to the down-regulation of the activity of ADH or ALDH. Alcohol clearance drugs and functional foods containing natural products can help improve the activity of these enzymes. However, because of the toxicity and side effects of drugs, there is a need for the development of healthy drinks that contain a safer natural product. Recently, the development of healthy functional foods that activate ADH and ALDH has focused on the reduction of blood alcohol levels. In this study, A. okamotoanum sap decreased the blood levels of ethanol and acetaldehyde significantly when compared with ethanol treatment alone (negative control) or with the positive control, 3 and $5 \mathrm{~h}$ after ethanol treatment, which suggests that A. okamotoanum sap is beneficial for the clearance of alcohol 
and acetaldehyde from the blood (Figs. 1 and 2). In addition, the mRNA expression levels of liver ADH and ALDH were significantly increased in animals pre-treated with 25,50 or $100 \%$ A. okamotoanum sap when compared with negative and positive controls (Figs. 3A and B), which suggests that pretreatment with the A. okamotoanum sap enhanced the alcohol metabolism rate in the rat liver.

The MEOS is another pathway of ethanol metabolism that catalyzes the conversion of ethanol to acetaldehyde. In chronic situations, the ADH pathway of ethanol metabolism switches to the pathway involving MEOS and CYP2E1 (14). The activation of CYP2E1 by ethanol is one of the main metabolic ethanol pathways and is responsible for the production of oxidative damage in hepatocytes (15). CYP2E1 is also expressed constitutively in isolated rat cardiomyocytes (16). Increased lipid peroxidation and CYP2E1 levels have been observed under chronic ethanol administration. In this study, the mRNA expression levels of liver CYP2E1 were increased in animals pre-treated with 25,50 or $100 \%$ A. okamotoanum sap when compared with positive controls (Fig. 4), which suggests that pre-treatment with 25,50 or $100 \%$ A. okamotoanum sap may still activate liver metabolism $7 \mathrm{~h}$ after administration. In our data, the increased mRNA expression of liver CYP2E1 was similar to chronic alcohol administration.

Vitamin $\mathrm{C}$ plays a huge role in maintaining human health and preventing disease, however its physiological functions have not been fully defined. The most well-known functions of vitamin $\mathrm{C}$ are antioxidant activity, collagen synthesis, the cardiovascular system and the immune system. There are lots of efforts to reveal new functions of vitamin $\mathrm{C}$, and of course, it is possible that vitamin $\mathrm{C}$ directly decreases alcohol levels. However, we consider that it might act indirectly as a cofactor in several important enzyme reactions. Plant hormones are chemicals that regulate plant growth. They are numerous and have multiple functions related to plant growth. Among them, plant stress hormones activate cellular responses, and they have potential medical applications. For example, researchers have found that some plant stress hormones affect human cancer cells (17). Further investigations need to evaluate the alcohol reducing effect by vitamin $\mathrm{C}$ and plant hormones.

Ethanol may lead to oxidative insults via a reaction involving aldehyde oxidase and acetal aldehyde or NADH, which can dysregulate mitochondrial oxidative metabolism (18). The electron transport chain within mitochondria contributes significantly to the production of ROS and exposure to ethanol augments ROS production, which may be exacerbated by a decrease in mitochondrial antioxidant defenses (19). In addition to ROS production, alcohol exposure also impairs enzymatic and non-enzymatic mechanisms that protect cells against ROS, such as superoxide dismutase (SOD), catalase, glutathione peroxidase, glutathione reductase (GR), and glutathione (GSH) (20). Enhanced ROS production and compromised antioxidant activity result in oxidative stress, which has been demonstrated to play an important role in alcohol-induced liver injury $(15,21)$. Short-term ethanol intoxication induces oxidative stress, followed by mitochondrial dysfunction and apoptosis in rat hepatocytes (5). It is important to clarify the precise mechanism of ethanol-induced hepatocellular apoptosis and mitochondrial dysfunction, and, in particular, to evaluate the role of the anti-apoptotic protein $\mathrm{Bcl}-2$ and of the pro-apoptotic protein Bax in these mechanisms. Mitochondria in ethanol-fed Sod1 ${ }^{-/}$mice exhibit elevated levels of Bax, Bak and Bcl-xL. Immunoprecipitation studies revealed an increased association of Bax and Bak (22). In particular, Bax translocates from the cytosol to mitochondria during acute ethanol-induced apoptosis of rat hepatocytes, which results in oxidative stress. Mitochondrial Bax forms a protein complex with the mitochondrial voltage-dependent anion channel (VDAC), which suggests that Bax translocation from the cytosol to mitochondria leads to the subsequent formation of a Bax-VDAC complex that plays a crucial role in acute ethanolinduced hepatocyte apoptosis (23). In this study, pre-treatment with 25,50 or $100 \%$ A. okamotoanum sap significantly decreased Bax expression and increased Bcl-2 expression $7 \mathrm{~h}$ after alcohol administration when compared with the negative control. The data suggest that A. okamotoanum sap pre-treatment may reduce the alcohol-induced oxidative stress in the liver of rats.

In conclusion, A. okamotoanum sap pre-treatment may significantly increase the mRNA expression levels of liver ADH and ALDH, and decrease ethanol and acetaldehyde concentrations in blood. Therefore, drinks containing A. okamotoanum sap may potentially be used for alcohol detoxification.

\section{Acknowledgements}

This study was supported by the Korea Forest Research Institute.

\section{References}

1. Aberle NS II, Burd L, Zhao BH and Ren J: Acetaldehyde-induced cardiac contractile dysfunction may be alleviated by vitamin $\mathrm{B} 1$ but not by vitamins B6 or B12. Alcohol Alcohol 39: 450-454, 2004.

2. Angeles G, Bond B, Boyer JS, Brodribb T, Brooks JR, Burns MJ, Cavender-Bares J, Clearwater M, Cochard H, Comstock J, Davis SD, Domec JC, Donovan L, Ewers F, Gartner B, Hacke U, Hinckley T, Holbrook NM, Jones HG, Kavanagh K, Law B, López-Portillo J, Lovisolo C, Martin T, Martínez-Vilalta J, Mayr S, Meinzer FC, Melcher P, Mencuccini M, Mulkey S, Nardini A, Neufeld HS, Passioura J, Pockman WT, Pratt RB, Rambal S, Richter H, Sack L, Salleo S, Schubert A, Schulte P, Sparks JP, Sperry J, Teskey R and Tyree M: The cohesion-tension theory. New Phytologist 163: 451-452, 2004.

3. Kunkel G: Plants for human consumption. Economic Botany 39: 176,1984

4. Jagota SK and Dani HM: A new colorimetric technique for the estimation of vitamin $\mathrm{C}$ using Folin phenol reagent. Anal Biochem 127: 178-182, 1982.

5. Cahill A, Cunningham CC, Adachi M, et al: Effects of alcohol and oxidative stress on liver pathology: the role of the mitochondrion. Alcohol Clin Exp Res 26: 907-915, 2002.

6. Yang H, Lee MK and Kim YC: Protective activities of stilbene glycosides from Acer mono leaves against $\mathrm{H}_{2} \mathrm{O}_{2}$-induced oxidative damage in primary cultured rat hepatocytes. J Agric Food Chem 53: 4182-4186, 2005

7. Yang H, Sung SH and Kim YC: Two new hepatoprotective stilbene glycosides from Acer mono leaves. J Nat Prod 68: 101-103, 2005.

8. Lee GS, Byun HS, Kim MH, et al: The beneficial effect of the sap of Acer mono in an animal with low-calcium diet-induced osteoporosis-like symptoms. Br J Nutr 100: 1011-1018, 2008.

9. Damodara Reddy V, Padmavathi P and Varadacharyulu NC: Effect of Emblica officinalis against alcohol-induced biochemical changes in plasma and red blood cells of rats. African J Biochem Res 1: 101-105, 2007.

10. Alcazar Arroyo R: Electrolyte and acid-base balance disorders in advanced chronic kidney disease. Nefrologia 28 (Suppl 3): S87-S93, 2008 (In Spanish). 
11. McIntyre N: The effects of alcohol on water, electrolytes and minerals. Contemp Issues Clin Biochem 1: 117-134, 1984.

12. Ylikahri RH, Leino T, Huttunen MO, Poso AR, Eriksson CJ and Nikkila EA: Effects of fructose and glucose on ethanol-induced metabolic changes and on the intensity of alcohol intoxication and hangover. Eur J Clin Invest 6: 93-102, 1976.

13. Lieber CS and Abittan CS: Pharmacology and metabolism of alcohol, including its metabolic effects and interactions with other drugs. Clin Dermatol 17: 365-379, 1999.

14. Tanaka E, Terada M and Misawa S: Cytochrome P450 2E1: its clinical and toxicological role. J Clin Pharm Ther 25: 165-175, 2000.

15. Cederbaum AI, Wu D, Mari M and Bai J: CYP2E1-dependent toxicity and oxidative stress in HepG2 cells. Free Radic Biol Med 31: 1539-1543, 2001

16. Thum $\mathrm{T}$ and Borlak J: Cytochrome P450 mono-oxygenase gene expression and protein activity in cultures of adult cardiomyocytes of the rat. Br J Pharmacol 130: 1745-1752, 2000.

17. Fingrut $\mathrm{O}$ and Flescher E: Plant stress hormones suppress the proliferation and induce apoptosis in human cancer cells. Leukemia 16: 608-616, 2002.
18. Montine KS, Reich E, Neely MD, et al: Distribution of reducible 4-hydroxynonenal adduct immunoreactivity in Alzheimer disease is associated with APOE genotype. J Neuropathol Exp Neurol 57: 415-425, 1998.

19. Hoek JB, Cahill A and Pastorino JG: Alcohol and mitochondria: a dysfunctional relationship. Gastroenterology 122: 2049-2063, 2002.

20. Wu D and Cederbaum AI: Alcohol, oxidative stress, and free radical damage. Alcohol Res Health 27: 277-284, 2003.

21. Dey A and Cederbaum AI: Alcohol and oxidative liver injury. Hepatology 43 (Suppl 1): S63-S74, 2006.

22. Kessova IG and Cederbaum AI: Mitochondrial alterations in livers of Sod1 ${ }^{-/}$mice fed alcohol. Free Radic Biol Med 42: 1470-1480, 2007.

23. Adachi M, Higuchi H, Miura S, et al: Bax interacts with the voltage-dependent anion channel and mediates ethanol-induced apoptosis in rat hepatocytes. Am J Physiol Gastrointest Liver Physiol 287: G695-G705, 2004. 